\title{
Two new species of Russula from Northeast China
}

\author{
Li GJ ${ }^{1,2}$, Zhang $\mathrm{CL}^{1}$, Zhao $\mathrm{RL}^{2,3^{*}}$ and Lin $\mathrm{FC}^{1^{*}}$ \\ ${ }^{1}$ State Key Laboratory for Rice Biology, Institute of Biotechnology, Zhejiang University, Hangzhou 310058, China \\ ${ }^{2}$ State Key Laboratory of Mycology, Institute of Microbiology, Chinese Academy of Sciences, No. 1 West Beichen Rd, \\ Chaoyang District, Beijing 100101, China \\ ${ }^{3}$ College of Life Sciences, University of Chinese Academy of Sciences, Huairou District, Beijing 100408, China
}

Li GJ, Zhang CL, Zhao RL, Lin FC 2018 - Two new species of Russula from Northeast China. Mycosphere 9(3), 431-443, Doi 10.5943/mycosphere/9/3/1

\begin{abstract}
Two new species of the genus Russula from northeastern China are described and illustrated based on phylogenetic analysis of internal transcribed spacer (ITS) ribosomal DNA sequences and morphological examination. These two new species are $R$. heilongjiangensis (from subsect. Maculatinae) and R. khinganensis (from subsect. Puellarinae). The morphological and molecular analyses support their taxonomic classification. A comparison of these new species and other similar species is also addressed in this paper.
\end{abstract}

Key words - Agaricomycetes - morphology - phylogeny - Russulaceae - Russulales - taxonomy

\section{Introduction}

The genus Russula Pers. is one of the most conspicuous gill mushroom groups among Basidiomycetes. It is characterized by a heteromerous context and amyloid spore ornamentation (Romagnesi 1967, 1985, Sarnari 1998, 2005, Li 2014). This genus contains hymenoid and sequestrate species, and the latter claim has been widely proved by molecular phylogenetic analyses (Lebel \& Tonkin 2007, Buyck et al. 2010). Basidiocarps of Russula are common in various boreal forests (Romagnesi 1967, 1985, Sarnari 1998, Li 2014) and form an ectomycorrhizal system in association with diverse host plants (Trappe 1962, Roberts et al. 2004). The basidiocarps of a number of Russula species are collected for food and medicine (Buyck 2008, Dai \& Yang 2008, Dai et al. 2010, Li et al. 2010), and a few red-capped species of Russula have an acrid taste when eaten raw or undercooked ( $\mathrm{Li}$ et al. 2010, Bau et al. 2014, Li 2014); however, some species are poisonous ( $\mathrm{Li}$ et al. 2010, Li 2014). Phylogenetic analyses of Russula and Russulaceae were carried out to investigate the relationship of infrageneric groups and monophyly of the genus (Eberhardt 2002, Miller \& Buyck 2002, Park et al. 2013, Adamčík et al. 2016a, 2016b). Although Russula was shown to be paraphyletic in some early phylogenetic analyses (Miller et al. 2001, 2006, Shimono et al. 2004), additional analyses suggested that Russula is a monophyletic genus (Eberhardt 2002, Larsson \& Larsson 2003, Buyck 2008, Buyck et al. 2010, Zhao et al. 2017). To establish new Russula taxa, internal transcribed spacer (ITS) phylogeny is commonly used as evidence. In recent years, Asia has become a hot spot for the exploration of unknown Russula species (Li 2014, Li et al. 2015).

Northeast China, historically known as Manchuria, consists of the three provinces of Heilongjiang, Jilin, and Liaoning and the eastern part of the Inner Mongolia Autonomous Region. 
The temperate continental climate of this region often means a long and cold winter and a short and rainy summer. In terms of flora, Northeast China includes the Eurasian forest subregion and SinoJapanese subregion of the Holarctic region (Wu 1979). The three main mountain formations are the Changbai, Greater, and Lesser Khingan mountains, which contain subfrigid coniferous forests, temperate coniferous and broad-leaved forests, and broad-leaved deciduous forests. The main tree species of Northeast China are Betula platyphylla, B. schmidtii, Larix gmelinii, Pinus koraiensis, P. sylvestris var. Mongolica, Populus davidiana, and Quercus mongolica (Xu 1998). Many mountainous areas contain the best conserved forests in China (Gu 1986, Ding \& Kang 1994), which facilitate the fruiting of Russula. Although dozens of Russula species were identified in different parts of the local fungal flora (Dai \& Bau 2007, Li \& Bau 2003, Bau et al. 2007, Bau 2012, Wang \& Bau 2015), a thorough study of this genus in Northeast China is still not available. The flora of Russula in this region is an intermixture of European, North American, and Asian species (Li 2014). Three new species and three new Chinese records of Russula have been reported in this region ( $\mathrm{Li}$ et al. 2012, 2013, Liu et al. 2017, Jiang et al. 2017).

During a mushroom survey in Northeast China in 2016, two novel Russula species were identified, based on morphological and molecular phylogenetic analyses. They are described and illustrated herein with morphological details. Other species similar in morphology and phylogeny to these new species are also discussed.

\section{Materials \& Methods}

\section{Morphological analyses}

Specimens were photographed with a Cannon EOS 7D Mark II digital camera (Utsunomiya, Japan). Macromorphological characteristics were recorded in detail, in the field and in daylight, based on fresh basidiocarps. Names and codes of the colors in the description follow those of Ridgway (1912). For permanent conservation, the specimens were dehydrated in a fruit dryer at $60^{\circ} \mathrm{C}$ until their water content fell below $10 \%$. Rehydration of the dried specimens was carried out in 5\% KOH. A solution of Congo Red was used for microscopic measurements and line drawing. Sulfovanillin (SV) and Melzer's reagent were employed for chemical reaction tests of basidiospore ornamentation and cystidium content. The rehydrated lamellae and pileus epidermis were sliced by hand with a razor blade before microscopic examination under a Nikon Eclipse 80i microscope (Tokyo, Japan). Basidiospores, basidia, and cystidia elements of the pileipellis and stipitipellis were examined and measured. Lengths of the apiculus and spore ornamentation were excluded from measurements. At least 20 elements were measured for each characteristic. An FEI Quanta 200 electron microscope (Hillsboro, OR, USA) was used for scanning electron microscopy. Herbarium name abbreviations followed those of Thiers (2018). The abbreviation $[a / b / c]$ indicates that $a$ basidiospores were measured in $b$ fruit bodies of $c$ specimens. Basidiospore dimensions are displayed as $(w-) x-y(-z), x-y$, which is the range including $95 \%$ or more of the measured values, while $w$ and $z$ are extremes of all the measured values. Q stands for the ratio basidiospore length/width. Bold $\mathbf{Q}$ represents the average value of $\mathbf{Q}$ plus or minus the standard deviation. Additional microscopic examination details in this study are explained in articles by Li et al. (2012, 2015), Li (2014). Comparison of selected morphological characteristics of the new species and closely related species were provided in Tables 1,2. Specimens of the two new taxa were deposited in Herbarium Mycologicum, Academiae Sinicae (HMAS).

\section{Phylogenetic analyses}

DNA extraction procedures were performed with the GeneOn Plant DNA Extraction Kit (GeneOn BioTech, Changchun, China) by the magnetic bead method. The ITS sequences were amplified with primer pairs ITS1/ITS4, LROR/LR5, and NS1/NS4 (White et al. 1990, Hibbett 1996, Moncalvo et al. 2000, 2002). Polymeric chain reaction (PCR) was carried out on a Veriti 96Well Thermal Cycler (Thermo Fisher Scientific, MA, USA) according to the reaction conditions of Li (2014). PCR products were purified and sequenced with the same primers as mentioned above 
Table 1 A comparison of selected morphological characteristics of $R$. heilongjiangensis and closely related species.

\begin{tabular}{|c|c|c|c|c|c|c|c|}
\hline Taxon & Pileus color & $\begin{array}{l}\text { Pileus diameter } \\
(\mathrm{mm})\end{array}$ & $\begin{array}{l}\text { Basidiospo } \\
\text { re } \\
\text { dimensions } \\
(\mu \mathrm{m})\end{array}$ & $\begin{array}{l}\text { Basidiospore } \\
(\mu \mathrm{m})\end{array}$ & dimensions & $\begin{array}{l}\text { Pileocystidia } \\
\text { dimensions }(\mu \mathrm{m})\end{array}$ & Habitats \\
\hline Russula dryadicola & $\begin{array}{l}\text { purple, often } \\
\text { fading to } \\
\text { yellow }\end{array}$ & $40-60$ & $\begin{array}{l}8.5-11.5 \times \\
7.5-10\end{array}$ & $\begin{array}{l}\text { mostly isolated, } 0.9-1.3 \mu \mathrm{m} \text { in } \\
\text { height, rarely linked, not } \\
\text { reticulate }\end{array}$ & $50-62 \times 10.5-15.5$ & $75-130 \times 9.5-16.5$ & $\begin{array}{l}\text { alpine zone, associated } \\
\text { with Dryas and } \\
\text { Juniperus }\end{array}$ \\
\hline $\begin{array}{l}\text { Russula } \\
\text { heilongjiangensis }\end{array}$ & bright red & $28-52$ & $\begin{array}{l}6.8-10 \times \\
5.6-8.3\end{array}$ & $\begin{array}{l}\text { mostly isolated, rarely linked as } \\
\text { short crests } 0.7-1 \mu \mathrm{m} \text { in height, } \\
\text { not reticulate }\end{array}$ & $34-46 \times 9-13$ & $68-101 \times 9-12$ & $\begin{array}{l}\text { coniferous and broad- } \\
\text { leaved intermixed } \\
\text { forests, with Betula, } \\
\text { Pinus, and Xylosma }\end{array}$ \\
\hline Russula globispora & $\begin{array}{l}\text { variously } \\
\text { colored, } \\
\text { sometimes } \\
\text { violet to } \\
\text { cooper brown }\end{array}$ & $40-100$ & $\begin{array}{l}9.7-12.4 \times \\
8.1-9.7\end{array}$ & $\begin{array}{l}\text { Ornamentation } 0.8-1.1 \mu \mathrm{m} \text { high, } \\
\text { mostly isolated, rarely fused in } \\
\text { pairs }\end{array}$ & $41-53 \times 12-17$ & $60-95 \times 12-16.5$ & deciduous forest \\
\hline Russula maculata & red to orange & $45-130$ & $\begin{array}{l}8.3-10.2 \times \\
6.5-8.6\end{array}$ & $\begin{array}{l}\text { ornamentation } 0.6-0.7 \mu \mathrm{m} \text { in } \\
\text { height, linked as lines, partly } \\
\text { reticulate, rarely isolated }\end{array}$ & $39-60 \times 12-15$ & $59-90 \times 11.5-14$ & $\begin{array}{l}\text { deciduous forest, often } \\
\text { under oaks of calcareous } \\
\text { soil }\end{array}$ \\
\hline Russula nympharum & $\begin{array}{l}\text { cream, rose to } \\
\text { orange }\end{array}$ & up to 100 & $\begin{array}{l}8.3-10.8 \times \\
6.5-7.9\end{array}$ & $\begin{array}{l}\text { ornamentation } 0.3-0.6 \mu \mathrm{m} \text { high, } \\
\text { often connected with fine lines, } \\
\text { rarely reticulate }\end{array}$ & $39-62 \times 9-14$ & $60-140 \times 8-15$ & $\begin{array}{l}\text { deciduous forest, often } \\
\text { under Quercus and } \\
\text { Arbutus }\end{array}$ \\
\hline
\end{tabular}

Table 2 A comparison of selected morphological characteristics of $R$. khinganensis and closely related species.

\begin{tabular}{|c|c|c|c|c|c|c|c|}
\hline Taxon & Pileus color & $\begin{array}{l}\text { Pileus } \\
(\mathrm{mm})\end{array}$ & $\begin{array}{l}\text { Basidiospore } \\
\text { print } \\
\text { (Romagnesi) }\end{array}$ & $\begin{array}{l}\text { Basidiospore dimensions } \\
(\mu \mathrm{m})\end{array}$ & $\begin{array}{l}\text { Basidia dimensions } \\
(\mu \mathrm{m})\end{array}$ & $\begin{array}{l}\text { Pileocystidia dimensions } \\
(\mu \mathrm{m})\end{array}$ & Context odor \\
\hline $\begin{array}{l}\text { Russula } \\
\text { khinganensis }\end{array}$ & bright red & $28-52 \mathrm{~mm}$ & III $b-c$ & $6.8-10 \times 5.6-8.3$ & $34-46 \times 9-13$ & $68-101 \times 9-12$ & not distinct \\
\hline Russula minutalis & $\begin{array}{l}\text { reddish violet } \\
\text { to brown }\end{array}$ & - & IIc & $6.5-8 \times 5-6.5$ & - & - & - \\
\hline Russula puellaris & $\begin{array}{l}\text { reddish violet } \\
\text { to brown }\end{array}$ & $32-60 \mathrm{~mm}$ & IIc & $7-9 \times 5.7-7.2$ & $34-50 \times 11.5-16$ & $50-74 \times 10-15$ & not distinct \\
\hline $\begin{array}{l}\text { Russula } \\
\text { terenopus }\end{array}$ & violet to brown & $20-50 \mathrm{~mm}$ & IId & $6.5-8.2 \times 5.4-6.4$ & $32-45 \times 8-12$ & $50-70 \times 6-14$ & $\begin{array}{l}\text { Pelargonium smell, } \\
\text { strong and lingering }\end{array}$ \\
\hline Russula versatilis & $\begin{array}{l}\text { reddish violet, } \\
\text { fading to } \\
\text { yellow }\end{array}$ & $30-60 \mathrm{~mm}$ & III b-c & $7-9 \times 5.5-7$ & $30-40 \times 8-11.5$ & $40-75 \times 8-13.5$ & $\begin{array}{l}\text { Pelargonium smell, } \\
\text { fainter and less lingering }\end{array}$ \\
\hline
\end{tabular}


by Majorbio Co., Ltd. (Shanghai, China) on an ABI 3730XL DNA analyzer with the ABI BigDye 3.0 Terminator Cycle Sequencing Kit (Applied Biosystems, CA, USA). Newly obtained raw sequences were spliced and deposited in GenBank (accession numbers are shown in Figs 1, 2). A total of 73 ITS sequences of closely related Russula taxa, including two specimens of $R$. emetica (Schaeff.) Pers. as an outgroup, were retrieved from the GenBank database. The alignment matrices were deposited in TreeBASE (ID 22710). Bayesian analyses (BA) were conducted in MrBayes 3.2.6 (Ronquist \& Huelsenbeck 2003). The evolutionary best-fit models of Bayesian analysis (BA) were conducted in MrBayes 3.2.6 (Ronquist \& Huelsenbeck 2003). The evolutionary best-fit model were evaluated by means of MrModelTest 2.3 (Nylander 2004) before analysis. Posterior probabilities (PPs) were calculated by the Markov chain Monte Carlo algorithm (Larget \& Simon 1999). A run of $1,000,000$ generations with the trees sampled every $100^{\text {th }}$ generation was carried out for three heated and one cold Markov chain. Automated termination was executed when the average standard deviation of split frequencies fell below 0.01 during the analysis. The first $25 \%$ of trees were discarded as burn-in data (Hall 1999). Maximum parsimony (MP) analysis was carried out in the PAUP* software v.4.01 (Swofford 2004). Gaps in the alignment were treated as missing data, and all sites were regarded as unordered and unweighted. The tree bisection-reconstruction algorithm was used in a heuristic search, and bootstrap support (BS) was analyzed with 1000 replicates (Felsenstein 1985). The "Maxtrees" parameter was set to 5000 , branches of zero length were collapsed, and all the most parsimonious trees were saved. Clade stability was assessed in a bootstrap analysis with 1000 replicates, each with 10 replicates of random stepwise addition of taxa. The Kishino-Hasegawa test (Kishino \& Hasegawa 1989) was performed to determine whether trees were significantly different. Trees were depicted in TreeGraph 2.4.0 (Stöver \& Müller 2010).

\section{Results}

The dataset for phylogenetic analyses of Russula subsect. Maculatinae contained 36 ITS sequences (average length $561 \mathrm{bp}$ ), representing 21 taxa; these sequences were studied by the MP method and BA. In the MP analysis, 380 characters were constant, 16 variable characters were parsimony-uninformative, and 205 characters were parsimony-informative. One most parsimonious tree was found in the heuristic search. The tree has a consistency index of 0.640 , a retention index of 0.887 , a rescaled consistency index of 0.568 , a homoplasy index of 0.360 , and a tree length of 450. Only a few minor differences in terminal topology were observed among trees by MP analysis and BA. Phylogenetic topology obtained by BA is shown in Figure 1. Clades of $R$. globispora and $R$. maculata complexes in this analysis corresponded to those of Adamčík et al. (2016a). Russula heilongjiangensis clustered with $R$. dryadicola, $R$. maculata, and two unrecognized taxa with strong support (PP 1.00, BS 99\%).

The dataset for phylogeny analyses of $R$. subsect. Puellarinae Singer contained 43 ITS sequences (average $601 \mathrm{bp}$ ), representing 17 taxa, were analyzed by MP and BA. In the MP analysis, 382 characters were constant, 44 variable characters were parsimony-uninformative, and 135 characters were parsimony-informative. One of the four most parsimony trees which was found in the heuristic search was presented in Figure 2. The tree has a CI of 0.639, an RI of 0.777, an RC of 0.496 , an HI of 0.361 , and a TL of 360. Some rearrangements in terminal topology could be observed between parsimony trees and the Bayesian tree. Members of $R$. subsect. Puellarinae, including the new species $R$. khinganensis, formed a well-supported monophyletic clade (PP 1.00, BS 100\%). Although the phylogenetic topology of $R$. subsect. Puellarinae were still not stable, the long phylogenetic distance between $R$. khinganensis and the other members of this section was enough to support it as an independent species.

\section{Taxonomy}

Russula heilongjiangensis G.J. Li \& R.L. Zhao, sp. nov. Fungal Names number: FN570531; Facesoffungi number: FoF03951 
Etymology - refers to Heilongjiang Province, the locality of the type specimen. Typus - China, Heilongjiang Province, Mudanjiang City, Muleng County, Liufengshan National

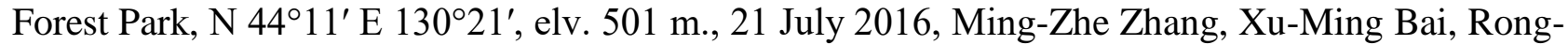
Chun Dai, Guo-Jie Li, ZRL20160516 (HMAS 255142), ITS: MG719932, nLSU: MH021611, nSSU: MH021633.

Diagnosis - the morphological characteristics of $R$. heilongjiangensis resemble those of $R$. maculata, but $R$. heilongjiangensis has smaller basidiocarps and shorter and narrower basidia.

Description - Basidiocarps small to medium-sized. Pileus $28-52 \mathrm{~mm}$ in diam., first hemispheric, then plano-convex, applanate when mature, often slightly depressed at the center, striate $\sim 3 \mathrm{~mm}$ from edge inward, sometimes cracked, slightly viscid when wet, peeling 1/4-1/3 from the edge, bright red tinges of Carmine (I1i), Begonia Rose (I1b), and Rose Doree (I3b) intermixed with small dark red patches of Dark Vinaceous (XXVII1"), Deep Corinthian Red (XXVII3"i), and Hydrangea Red (XXVII1"i), fading orange, pale yellowish brown to yellow tinges of Zinc Orange (XV13'), Sayal Brown (XXIX15") to Pale Orange Yellow (III17) at center. Lamellae adnate, 3-5 mm in height, 13-18 pieces per centimeter at edge, sometimes forked near stipe, often interveined, pale yellowish tinges of Martius Yellow (III23f), often slightly dotted with orange to pale brownish tinges of Yellow Ocher (XV17') to Sudan Brown (III15k) when bruised, lamellulae absent. Stipes central to subcentral, 4.2-6.5 ×0.9-1.6 cm, subcylindrical to cylindrical, surface dry, rugulose longitudinally, dull, without annulus, slightly attenuate upward, White (LIII), brownish yellow tinge of Tawny (XV13'i) when bruised and dry, stuffed at first, becoming hollow when old. Context up to 2-3 mm at center of pileus, White (LIII) first, turning Ochraceous-Orange (XV15'), Ochraceous-Tawny (XV15'i) to Buckthorn Brown (XV17'i) when bruised, fragile, no distinct odor; taste moderately acrid. Spore print Yellow (Romagnesi IV d-e).

Basidiospores [100/2/2] (6.8-) 7.4-9.4 (-10) $\times(5.6-)$ 5.9-8.3 $\mu \mathrm{m}, \mathrm{Q}=(1.06-)$ 1.12-1.33 (Q $=1.21 \pm 0.07)$, hyaline, subglobose to broadly ellipsoid, rarely ellipsoid; ornamentation composed of amyloid warts that are mostly isolated, rarely linked as short crests and ridges, not forming network, warts 0.7-1 $\mu \mathrm{m}$ high; suprahilar area amyloid and distinct. Basidia 34-46 $\times 9-13 \mu \mathrm{m}$, four-spored, sterigmata 3-6 $\mu \mathrm{m}$ long, hyaline, rarely yellowish in $\mathrm{KOH}$, subclavate to clavate, rarely cylindrical. Pleurocystidia scattered, 68-101 $\times 9-12 \mu \mathrm{m}$, distinctly projecting 30-50 $\mu \mathrm{m}$ beyond basidia, clavate to subclavate, sometimes fusoid, subfusoid to subcylindrical, apex rounded to obtuse, sometimes mucronate, thin-walled, contents fibrous to crystal, blackish gray in SV. Cheilocystidia not observed; lamellar edge sterile. Subhymenium: cellular layer 15-40 $\mu \mathrm{m}$ thick composed of inflated cells 8-20 $\mu \mathrm{m}$ in diam., hyaline, sometimes pale yellowish in $\mathrm{KOH}$. Pileipellis is composed of epipellis and subpellis; epipellis trichoderm 100-250 $\mu \mathrm{m}$ thick, composed of thin-walled, unbranched cylindrical hyaline hyphae 3-6 $\mu \mathrm{m}$ wide; pileocystidia rare, 6-8 $\mu \mathrm{m}$ wide with crystal contents greyish in SV, unseptate, clavate to cylindrical, apex round; subpellis: cutis 100-120 $\mu \mathrm{m}$ thick, composed of gelatinized, interweaved hyaline hyphae $2-5 \mu \mathrm{m}$ wide. Stipitipellis: cutis, upper layer composed of parallel filamentous hyphae 3-6 $\mu \mathrm{m}$ in diam., inner layer hyaline filamentous hyphae interweaved with sphaerocytes $15-25 \mu \mathrm{m}$ in diam., some filamentous hyphae pale yellow in $\mathrm{KOH}$; caulocystidia absent. Trama composed of sphaerocytes 15-40 $\mu \mathrm{m}$ in diam. and scattered by filamentous and cystidioid hyphae. Clamp connections and laticiferous hyphae absent in all tissues.

Habit and habitat - Single in coniferous and broad-leaved intermixed forests (dominated by e.g. Betula dahurica, B. platyphylla, Pinus bungeana, P. koraiensis, and Xylosma racemosum) at 400-600 m altitude.

Other specimens examined - China, Heilongjiang Province, Mudanjiang City, Muling County,

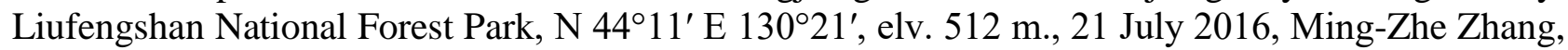
Xu-Ming Bai, Rong-Chun Dai, Guo-Jie Li, ZRL20164231 (HMAS 279587), ITS: MG719933, nLSU: MH021614, nSSU: MH021636.

Distribution - China (Heilongjiang). Season July and August.

Notes - The combination of a red pileus, yellow spore print, acrid-tasting context, and the absence of diverticula in pileipellis hyphae and pileocystidia contents turning grey in SV indicated 
that the new species $R$. heilongjiangensis is a member of Russula subsect. Maculatinae (Romagn.) Konrad \& Joss. described in Romagnesi $(1967,1985)$ and subsubsect. Urentes Maire described by Sarnari $(1998,2005)$, for which the name Maculatinae was more commonly used in some studies (Adamčík \& Jančovičová 2013, Adamčík et al. 2016a).

The most similar species in morphology is $R$. maculata from the $R$. maculata complex, which also has a red pileus without a purple tinge, yellow-brownish context discoloration, lamellae with yellow-brownish spots, basidiospores not exceeding $10.5 \times 9 \mu \mathrm{m}$, basidiospore ornamentation composed of amyloid warts often merged or connected by line connections. Nevertheless, these two species can be distinguished because $R$. maculata has a larger pileus [45-110 $\mathrm{mm}$ in diam. (Sarnari 1998)], longer and wider basidia (39-60 × 12-15 $\mu \mathrm{m}$ (Adamčík \& Jančovičová 2013)), and habitats of Quercus, Fagus, Carpinus, and Tilia forest (Adamčík et al. 2016a). The other recognized species from the $R$. maculata complex is $R$. nympharum $\mathrm{F}$. Hampe \& Marxm., which is different from $R$. heilongjiangensis by its lower basidiospore ornamentation $0.3-0.6 \mu \mathrm{m}$ and numerous pileocystidia (Adamčík et al. 2016a).

$R$. heilongjiangensis is close to the $R$. globispora complex in phylogeny. Presently, the $R$. globispora complex contains two species, which are closely related to $R$. heilongjiangensis. They can be distinguished from the new species by the following characteristics: $R$. dryadicola has a yellow and purple pileus without bright red tinges, high basidiospore ornamentation $(0.9-1.3 \mu \mathrm{m})$ composed of mostly isolated warts, and an alpine habitat associated with Dryas and Juniperus (Sarnari 1998); R. globispora has larger basidiospores $(9.7-12.4 \times 8.1-9.7 \mu \mathrm{m})$ and wider basidia (12-17 $\mu \mathrm{m}$ (Sarnari 1998, Adamčík \& Jančovičová 2013)). Thus, the morphological and phylogenetic analyses both support $R$. heilongjiangensis as a new species.

Russula khinganensis G.J. Li \& R.L. Zhao, sp. nov.

Fig. 4

Fungal Names number: FN570532; Facesoffungi number: FoF03952

Etymology - refers to Lesser Khingan Mountains, the locality of the type specimen.

Typus - China, Heilongjiang Province, Yichun City, Dailing District, Liangshui National

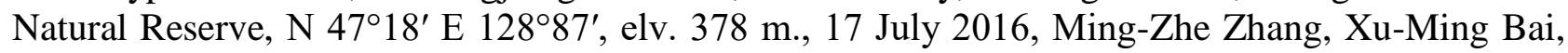
Rong-Chun Dai, Guo-Jie Li, ZRL20160285 (HMAS 278895), ITS: MG719928, nLSU: MH021612, nSSU: MH021634.

Diagnosis - Russula khinganensis is similar to $R$. versatilis in morphology, but $R$. khinganensis has smaller basidiocarps, narrower pleurocystidia, basidiospore ornamentation composed of short to long ridges, and a habitat of broad-leaved and coniferous intermixed forest.

Description - Basidiocarps small to medium sized. Pileus $26-38 \mathrm{~mm}$ in diam., hemispherical when young, turning applanate after maturation, with age depressed above stipe, slightly viscid when wet, greyish vinaceous tinges, Livid Brown (XXXIX1"'), Deep Livid Brown (XXXIX1"'i) to Russet Vinaceous (XXXIX9"') at center; margin incurved first, straight to slightly curled upward when mature, sometimes undulate and cracked, striate 5-10 mm from edge inward, peeling 1/4-1/2 toward the center, pale vinaceous tinges of Purplish Vinaceous (XXXIX1"'b), Pale Purplish Vinaceous (XXXIX1"'f), and Pale Brownish Vinaceous (XXXIX3"'f) toward the margin; margin slightly striate. Lamellae adnate, $2-5 \mathrm{~mm}$ in height, 11-15 pieces per centimeter at edge, not forked, slightly interveined, ocherous-tinged, Pale Ochraceous-Salmon (XV13'f) to Pale Ochraceous-Buff (XV15'f) first, Light Ochraceous-Salmon (XV13'd) to Ochraceous-Buff (XV15'b) when mature, unchanging when bruised, lamellulae absent. Stipes central to subcentral, 4.5-7.7 $\times$ $0.8-1.5 \mathrm{~cm}$, subcylindrical to cylindrical, surface dry, rugulose longitudinally, dull, without annulus, tapering toward base, White (LIII), unchanging when old and bruised, stuffed at first, becoming hollow when old. Context $2-3 \mathrm{~mm}$ thick from lamellae attachment to stipe at pileus center, White (LIII), slowly and partly turning ocherous color of Yellow Ocher (XV17') after bruising for long time, compact under pileus; taste mild, sometimes slightly acrid in lamellae, no distinct odor. Spore print ocherous (Romagnesi III b-c).

Basidiospores [100/2/2] (6.0-) 6.3-7.3 (-7.6) × 5.2-6.4 (-6.7) $\mu \mathrm{m}, \mathrm{Q}=(1.07-)$ 1.10-1.25 $(-1.33)(\mathbf{Q}=1.18 \pm 0.05)$, hyaline to pale cream colored, subglobose to broadly ellipsoid, rarely 
globose or ellipsoid, verrucose; ornamentation amyloid, composed of verrucous to conical warts $0.5-1 \mu \mathrm{m}$ in height, rarely linked by fine lines as short to long ridges, partly reticulate, sometimes isolated; suprahilar area amyloid and distinct. Basidia 35-43 × 10-11 $\mu \mathrm{m}$, hyaline, clavate, ventricose toward upper half, four-spored, projecting 10-15 $\mu \mathrm{m}$ beyond hymenium; sterigmata 4-7 $\mu \mathrm{m}$, pointed, straight to slightly tortuous. Pleurocystidia 51-65 $\times 6-9 \mu \mathrm{m}$, originating from subhymenium, projecting 15-35 $\mu \mathrm{m}$ beyond hymenium, thin-walled, clavate to subclavate, sometimes subfusiform to fusiform, apex mucronate, at times constricted, often with moniliform or capitate appendage, contents crystal, blackish in SV. Cheilocystidia not observed; lamellar edge sterile. Subhymenium 20-40 $\mu \mathrm{m}$ thick, composed of slender cylindrical cells 4-10 $\mu \mathrm{m}$ wide under basidia and inflated elliptical to globose cells $25-50 \mu \mathrm{m}$ in diam. next to trama. Pileipellis 120-250 $\mu \mathrm{m}$ thick, composed of epipellis (50-70 $\mu \mathrm{m}$ thick) and subpellis (70-180 $\mu \mathrm{m}$ thick); epipellis trichoderm, composed of mostly ascending to suberect hyphae, intermixed with several repent and erect elements, $2-4 \mu \mathrm{m}$ in diam.; pileocystidia $37-55 \times 3-5 \mu \mathrm{m}$, cylindrical to subcylindrical, with round to obtuse tips, septate, contents dense, black in SV; subpellis composed of long, rarely septate, equally wide hyphae $2-4 \mu \mathrm{m}$ in diam. interweaved with sphaerocytes $20-35 \mu \mathrm{m}$ in diam. Stipitipellis: cutis composed of thin-walled, septate, cylindrical, hyaline to slightly yellowish hyphae 3-5 $\mu \mathrm{m}$ wide; terminal cells of stipitipellis hyphae with obtuse to tapered apex; caulocystidia not observed. Trama composed of sphaerocytes 20-50 $\mu \mathrm{m}$ in diam. and septate filamentous hyphae. Clamp connections and lacticiferous hyphae absent in all tissues.

Habit and habitat - Single or scattered in coniferous and broad-leaved intermixed forests, with Betula platyphylla, Larix gmelinii, Populus davidiana, and Picea koraiensis, at an altitude of 200-500 m.

Other specimens examined - China, Heilongjiang Province, Yichun City, Dailing District,

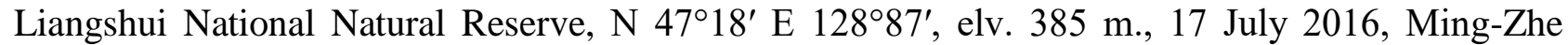
Zhang, Xu-Ming Bai, Rong-Chun Dai, Guo-Jie Li, ZRL20162112 (HMAS 279576), ITS: MG719929, nLSU: MH021613, nSSU: MH021635.

Distribution - China (Heilongjiang). Season July.

Notes - This new species belongs to $R$. subsect. Puellarinae owing to its small and slim basidiocarps, purple pileus without a red tinge, mild context taste, basidia less than $50 \times 12 \mu \mathrm{m}$, and septate pileocystidia without incrustation (Sarnari 1998). This section has been referred to as "series Puellaris ad int." (nom. inval.) within $R$. subsect. Puellarinae because of its yellowish context, ocher spore print, and isolated to subridged basidiospore ornamentation (Sarnari 2005).

In "series Puellaris ad int.," the species most similar to this new species is $R$. versatilis Romagn., because both have spore print IIIb-IIIc, an indistinct context odor, and a slightly less yellowish context of the "series." Nonetheless, $R$. versatilis is distinguishable from $R$. khinganensis by a larger pileus (up to $55 \mathrm{~mm}$ in diam.), which is often variable and fading, wider pleurocystidia $(8-13.5 \mu \mathrm{m})$, basidiospore ornamentation composed of mostly isolated warts, and a habitat of a hornbeam forest. The other two species of "series Puellaris ad int." ( $R$. minutalis Britzelm. and $R$. puellaris Fr.) have paler, dark cream to ocherous spore print IIc-IId; $R$. puellaris Fr. also differs because of its brownish ocher fading pileus, all over a yellowish turning context, and larger basidiospores, 7-9 × 5.7-7.2 $\mu \mathrm{m}$. Russula terenopus Romagn. can be distinguished from the new species by its strong context odor of Pelargonium (Romagnesi 1967, Sarnari 2005). Thus, we proposed our specimens as a new species: $R$. khinganensis.

\section{Discussion}

The concept of $R$. subsect. Maculatinae was initially proposed under the name "Maculatae" (Konard \& Josserand 1934). Nonetheless, its morphological concept was still vague at the time. Not only the two commonly known species, $R$. maculata and $R$. badia Quél., but also two alien species, $R$. rubra Bres. and $R$. pseudointegra Arnould \& Goris, were regarded as its members (Konard \& Josserand 1934, Romagnesi 1967). This group was upgraded to the section level by Romagnesi using the current name (Romagnesi 1962). Its characteristic morphology was detailed in ref. (Romagnesi 1967), including the mainly reddish pileus, yellowish basidiospore print, 


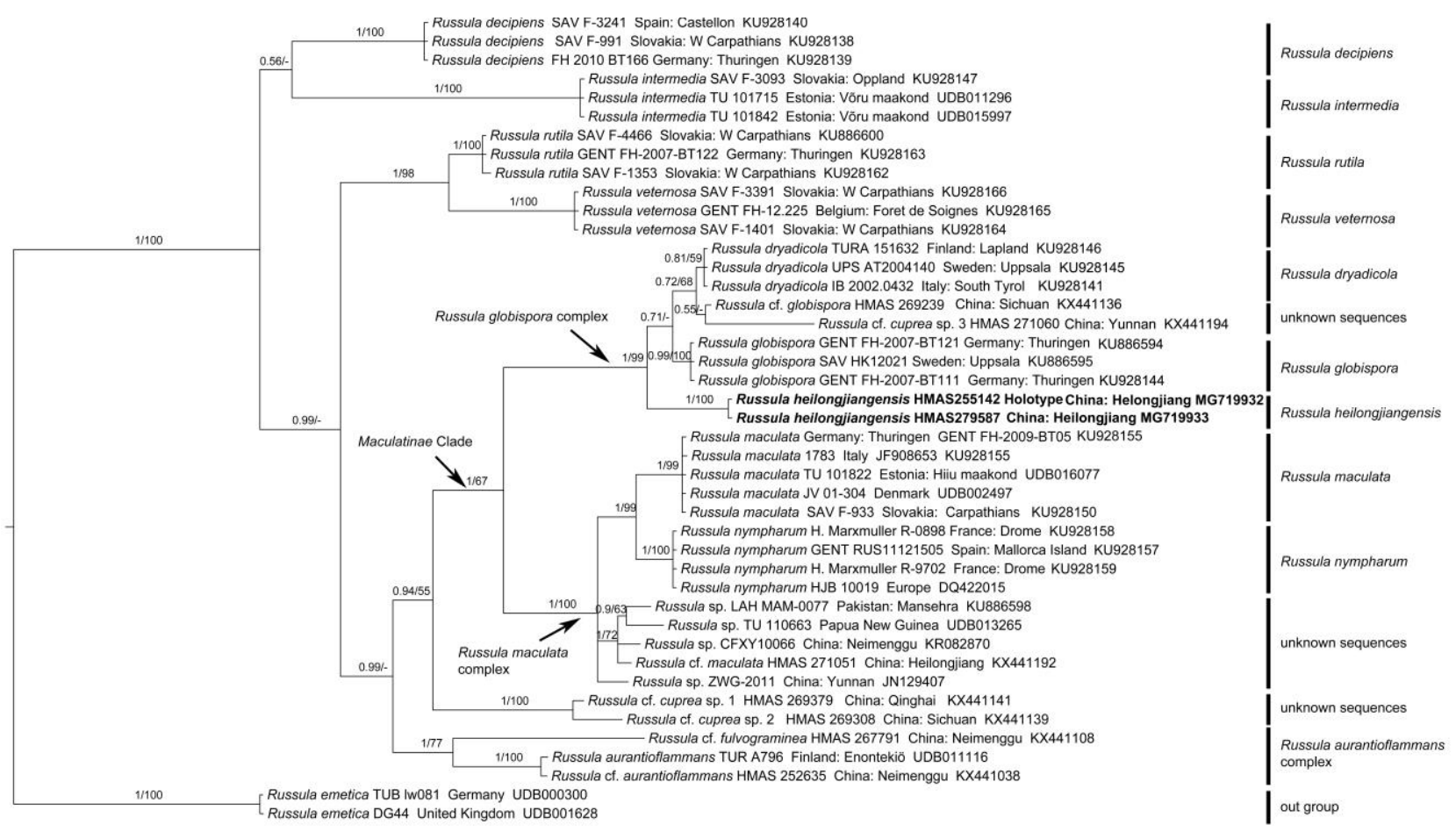

Figure 1 - Phylogeny of Russula subsect. Maculatinae in sense of Romagnesi (1967) and species with yellow-brownish generated from the Bayesian analysis of the ITS sequences. Bayesian posterior probability (PP) values and Bootstrap support (BS) values $>50 \%$ are given at the internodes (PP/BS).

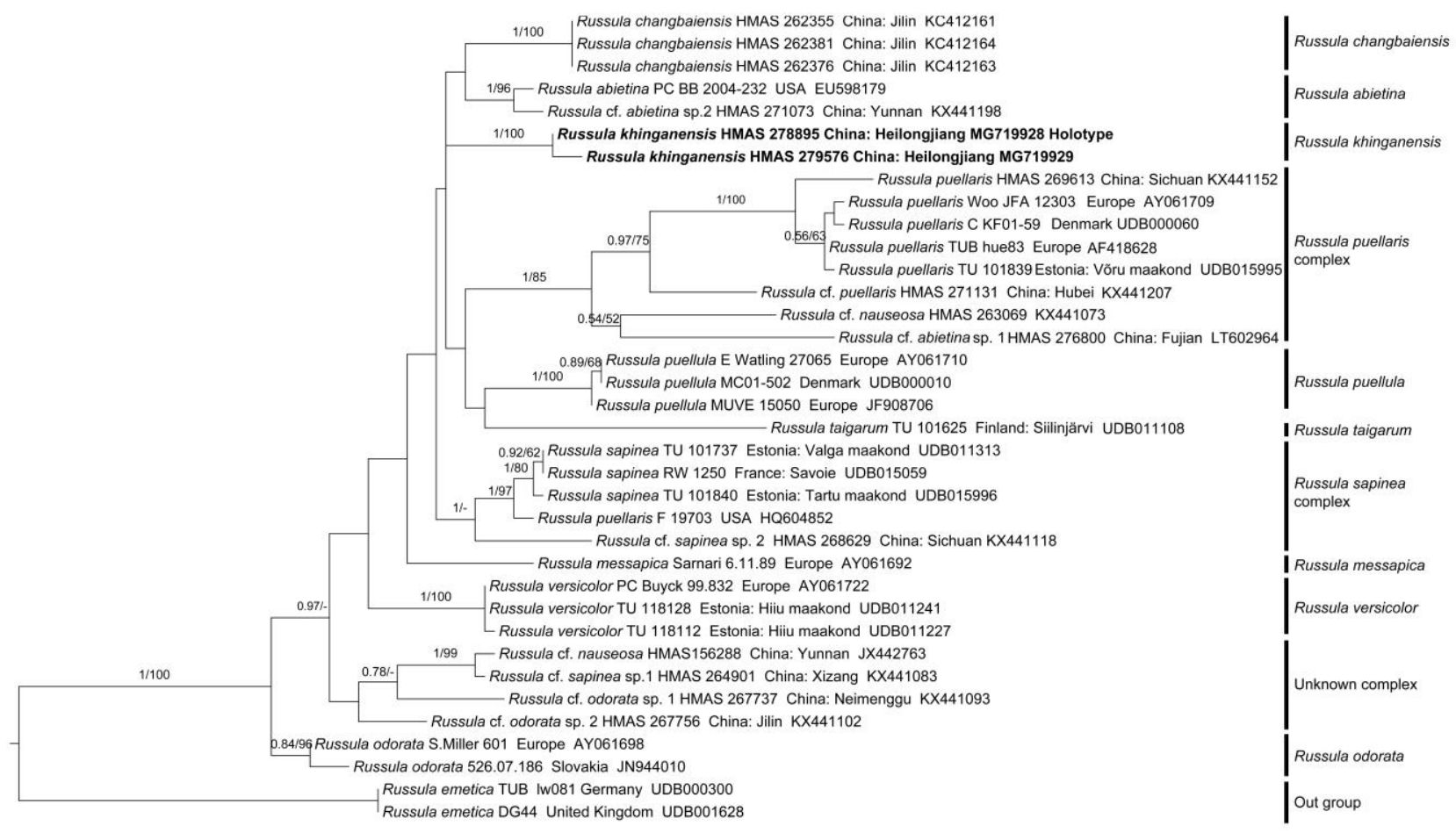

Figure 2 - Phylogeny of Russula subsect. Puellarinae generated by the MP analysis of ITS sequences. Bayesian posterior probability (PP) values and Bootstrap support (BS) values $>50 \%$ are given at the internodes (PP/BS). 

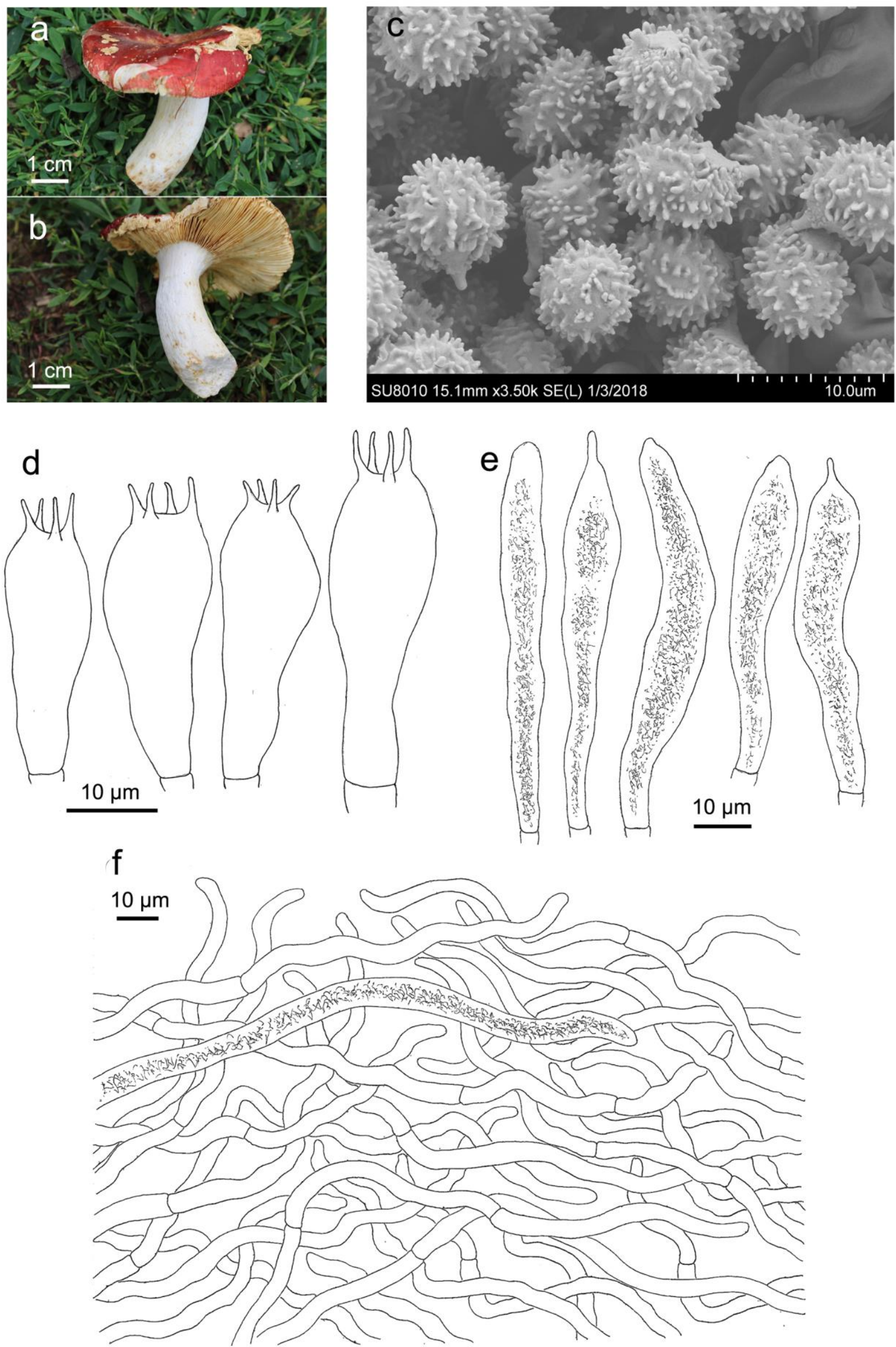

Figure 3 - Russula heilongjiangensis: ZRL20160516 (HMAS255142 holotype). a-b Basidiocarp. c Basidiospores. d Basidia. e Pleurocystidia. f Pileipellis (epipellis). 

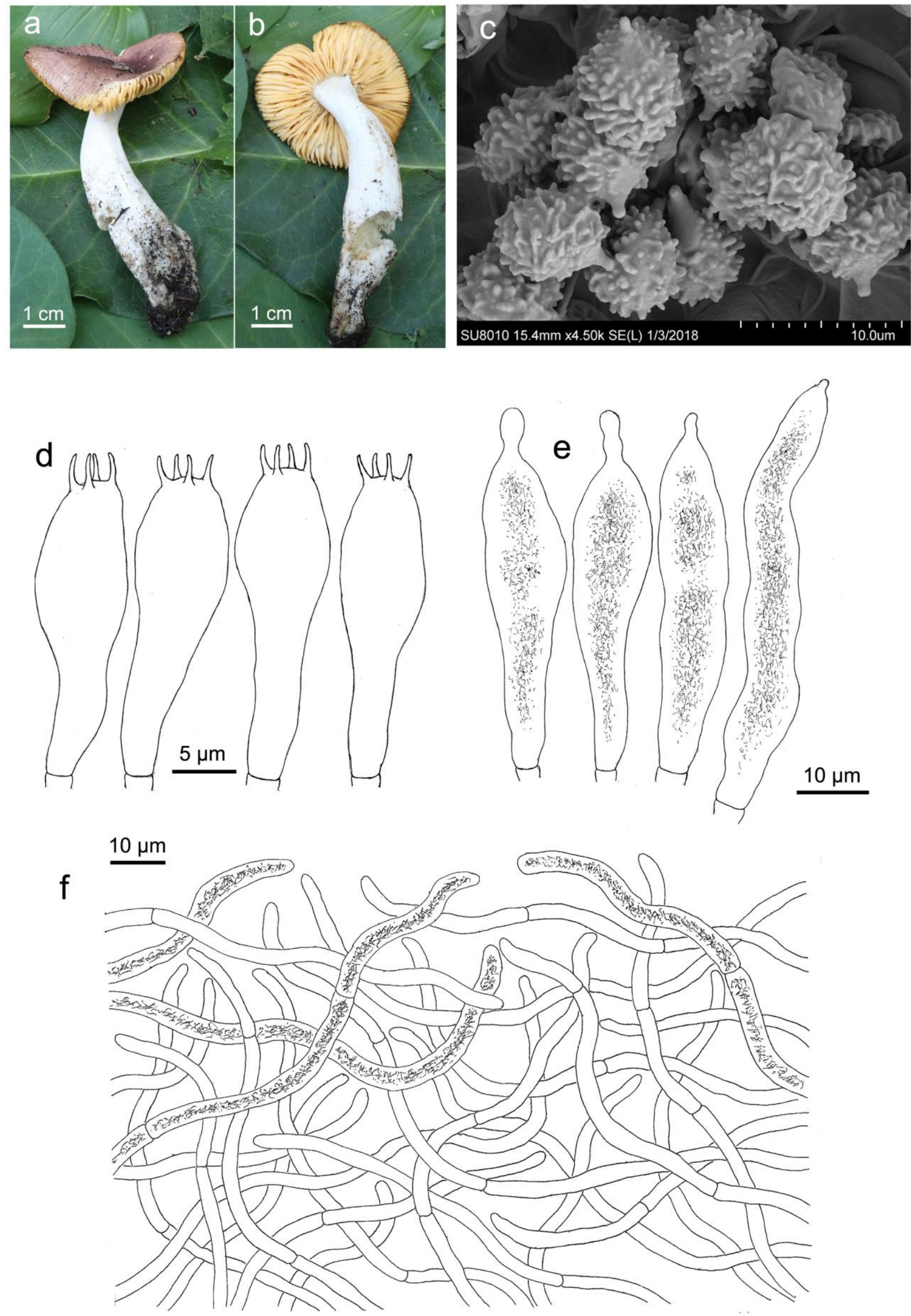

Figure 4 - Russula khinganensis: ZRL20160285 (HMAS278895 holotype) a, b Basidiocarp. c Basidiospores. d Basidia. e Pleurocystidia. f Pileipellis (epipellis). 
acrid-tasting context, pileipellis hyphae without diverticula, and greyish turning pileocystidia in SV. Members of this group were involved in $R$. subsect. Urentes Maire in ref. Sarnari (1998), which has a wider morphological concept. Precise and statistically supported descriptions for members of $R$. subsect. Maculatinae were presented in a recent work, detailed with widely used and newly introduced morphological characteristics (Adamčík \& Jančovičová 2012, 2013). At least three species can be recognized within the generally accepted morphological concept of $R$. maculata in phylogenetic analyses of the ITS region, including $R$. maculata, $R$. nympharum F. Hampe \& Marxm., and an unknown Pakistani species (Adamčík et al. 2016a). Although some specimens from Northeast and Southwest China were identified as members of $R$. subsect. Maculatinae, such as $R$. maculata and $R$. decipiens, none of these identifications was supported by phylogenetic analyses (Li 2014). The ITS phylogenetic topology in our study not only supports the independence of $R$. heilongjiangensis but also shows that there are still unknown species of $R$. subsect. Maculatinae in China.

Compared with the elaborate morphological and phylogenetic analyses of $R$. subsect. Maculatinae, less attention has been given to $R$. subsect. Puellarinae, even in Europe. The numerous members, e.g. 12 species in ref. Romagnesi (1967) and 17 species in Sarnari (2005), increase the difficulty with the taxonomy of $R$. subsect. Puellarinae. Five species of this subsection are distributed in China, among which the taxonomic identity of the European species $R$. puellaris is supported by both morphological and phylogenetic evidences (Li 2014). Russula khinganensis is the second species in Northeast China that was described after $R$. changbaiensis G.J. Li \& H.A. Wen (Li et al. 2013b).

\section{Acknowledgements}

This work was supported by grants from the National Natural Science Foundation of China (Project IDs GJL: 31500013, RLZ: 31470152 and 31360014), the National Project on Scientific Groundwork for Basic Science of the Ministry of Science and Technology (No. 2014FY210400), and the Foundation of Innovative Group of Edible Mushrooms Industry of Beijing (Project ID: BAIC05-2017). Xu-Ming Bai, Ming Zhe Zhang, and Rong-Chun Dai are acknowledged for helping with specimen collection. The authors are grateful to Liu Yang for the loan of herbarium specimens, to Chun-Li Li and Xiao-Lan Zhang (Institute of Microbiology, Chinese Academy of Sciences) for helping with scanning electron microscopy, and to Yan-Lei Ding and Xin-Yu Zhu (Baotou Normal College) for assistance with DNA extraction and sequencing.

\section{References}

Adamčík S, Jančovičová S. 2012 - Type studies in Russula subsection Maculatinae: R. decipiens and related taxa as interpreted by H. Romagnesi. Cryptogamie Mycologie 33(4), 411-420.

Adamčík S, Jančovičová S. 2013 - Type studies in Russula subsection Maculatinae and affiliated taxa: four species as interpreted by Henri Romagnesi. Sydowia 65(2), 201-222.

Adamčík S, Caboň M, Eberhardt U, Saba M et al. 2016a - A molecular analysis reveals hidden species diversity within the current concept of Russula maculata (Russulaceae, Basidiomycota). Phytotaxa 270(2), 71-88.

Adamčík S, Slovák M, Eberhardt U, Ronikier U et al. 2016b - Molecular inference, multivariate morphometrics and ecological assessment are applied in concert to delimit species in the Russula clavipes complex. Mycologia 108(4), 716-730.

Bau T. 2012 - List of agarics and boletoid fungi from eastern Inner Mongolia. Journal of Fungal Research 10(1), 20-30.

Bau T, Yevgeniya MB, Zhuang JY, Li Y. 2007 - Agarics and other macrobasidiomycetes from Ussuri River Valley. Mycosystema 26(3), 349-368.

Bau T, Bao HY, Li Y. 2014 - A revised checklist of poisonous mushrooms in China. Mycosystema 33(3), 517-548. 
Buyck B. 2008 - The edible mushrooms of Madagascar: An evolving enigma. Economic Botany 62 (3), 509-520.

Buyck B, Hofstetter V, Verbeken A, Walleyn R. 2010 - Proposal 1919: To conserve Lactarius nom. cons. (Basidiomycota) with a conserved type. Mycotaxon 111, 504-508.

Dai YC, Bau T. 2007 - Illustrations of edible and medicinal fungi of Northeast China. China Science Press, Beijing, 1-231.

Dai YC, Yang ZL. 2008 - A revised checklist of medicinal fungi in China. Mycosystema, 27(6): 801-824.

Dai YC, Zhou LW, Yang ZL, Wen HA et al. 2010 - A revised checklist of edible fungi in China. Mycosystema 29(1), 1-21.

Ding BL, Kang J. 1994 - Economic plants of the Greater Khingan Mountains. China Meteorological Press, Beijing, 1-317.

Eberhardt E. 2002 - Molecular kinship analyses of the agaricoid Russulaceae: Correspondence with mycorrhizal anatomy and sporocarp features in the genus Russula. Mycological Progress $1(2), 201-223$.

Felsenstein J. 1985 - Confidence intervals on phylogenetics: an approach using bootstrap. Evolution 39, 783-791.

$\mathrm{Gu}$ YC. 1986 - Forest resoureses in the forest region of the Greater Xinggan Mountains. Institute of Forest Inventory and Planning, Ministry of Forestry, Beijing, 1-113.

Hall TA. 1999 - BioEdit: a user-friendly biological sequence alignment editor and analysis program for Windows 95/98/NT. Nucleic Acids Symposium Series 41, 95-98.

Hibbett DS. 1996 - Phylogenetic evidence for horizontal transmission of Group I introns in the nuclear ribosomal DNA of mushroom-forming fungi. Mol Biol Evol 13, 903-917.

Jiang XM, Liang JF, Wu JR. 2017 - Russula brunneovinacea sp. nov., from northeastern China. Mycotaxon 132, 789-797.

Katoh K, Standley DM. 2013 - MAFFT multiple sequence alignment software version 7: improvements in performance and usability. Mol Biol Evol 30(4), 772-780.

Kishino H, Hasegawa M. 1989 - Evaluation of the maximum likelihood estimate of the evolutionary tree topologies from DNA sequence data, and the branching order in Hominoidea. Journal of Molecular Evolution 29, 170-179.

Konrad P, Josserand M. 1934. - Notes su la classification des Russules. Bull Soc Mycol Fr 50, 253-269.

Larget B, Simon DL. 1999 - Markov chain Monte Carlo algorithms for the Bayesian analysis of phylogenetic trees. Mol Biol Evol 16, 750-759.

Larsson E, Larsson KH. 2003 -Phylogenetic relationships of russuloid basidiomycetes with emphasis on aphyllophoralean taxa. Mycologia 95(6), 1037-1065.

Lebel T, Tonkin JE. 2007 - Australasian species of Macowanites are sequestrate species of Russula. Aust Sys Bot 20, 355-381.

Li Y, Bau T. 2003 - Mushroom of Changbai Mountains. Science Press, Beijing, 1-362.

Li GJ, Li SF, Wen HA. 2010 - The Russula species resource and its economic values of China. Acta Edulis Fungi 17(supl), 155-160

Li GJ, Li SF, Liu XZ, Wen HA. 2012 - Russula jilinensis sp. nov. (Russulaceae) from northeast China. Mycotaxon 120, 49-58.

Li GJ, Zhao D, Li SF, Yang HJ, Wen HA, Liu XZ. 2013 - Russula changbaiensis sp. nov. from northeast China. Mycotaxon 124, 269-278.

Li GJ. 2014 - Taxonomy of Russula from China. Ph.D. dissertation. Institute of Microbiology, Chinese Academy of Sciences \& University of Chinese Academy of Sciences, Beijing, 1-558.

Li GJ, Zhao D, Li SF, Wen HA. 2015 - Russula chiui and R. pseudopectinatoides, two new species from southwestern China supported by morphological and molecular evidence. Mycol Prog $14,33$.

Liu XL, Bau T, Wang XH. 2017 - Species diversity of Russula from the Greater and Lesser Hinggan Mountains in Northeast China. Mycosystema 36(10), 1355-1368. 
Miller SL, Buyck B. 2002 - Molecular phylogeny of the genus Russula in Europe with a comparison of modern infrageneric classifications. Mycol Res 106(3), 259-276.

Miller SL, McClean TM, Walker JF, Buyck B. 2001 - A molecular phylogeny of the Russulales including agaricoid, gasteroid and pleurotoid taxa. Mycologia 93(2), 344-354.

Miller SL, Larsson E, Larsson KH, Verbeken A, Nuytinck J. 2006 - Perspectives in the new Russulales. Mycologia 98(6), 960-970.

Moncalvo JM, Lutzoni FM, Rehner SA, Johnson J, Vilgalys R. 2000 - Phyligenetic relationships of Agaric fungi based on nuclear large subunit ribosomal DNA sequences. Syst Biol 49, 278305.

Moncalvo JM, Vilgalys R, Redhead SA, Johnson JE et al. 2002 - One Hundred and Seventeen Clades of Euagarics. Mol Phylogenet Evol 23, 357-400.

Nylander JAA. 2004 - MrModelTest v2. Program distributed by the author. Evolutionary Biology Centre, Uppsala University.

Park MS, Fong JJ, Lee H, Oh SY et al. 2013. -Delimitation of Russula subgenus Amoenula in Korea using three molecular markers. Mycobiology 41(4), 191-201.

Ridgway R. 1912 - Color standards and color nomenclature. Robert Ridgway, Washington, 1-270.

Roberts C, Ceska O, Kroeger P, Kendrick BW. 2004 - Macrofungi from six habitats over five years in Clayoquot Sound, Vancouver Island. Canadian Journal of Botany 82 (10), 1518-1538.

Ronquist F, Huelsenbeck JP. 2003 - MRBAYES 3: Bayesian phylogenetic inference under mixed models. Bioinformatics 19, 1572-1574.

Romagnesi H. 1962. - Taxa nova ex genere Russula.Bull Soc Linn Lyon 25:183.

Romagnesi H. 1967 - Russules d'Europe et d'Afique du Nord. Bordas, Paris, 1-998.

Romagnesi H. 1985 - Les Russules d' Europe et d'Afrique du Nord. Reprint with supplement. J. Cramer, Lehre, 1-1028.

Sarnari M. 1998 - Monografia illustrate de genere Russula in Europa. Tomo Primo. AMB, Centro Studi Micologici, Trento, 1-800.

Sarnari M. 2005 - Monografia illustrate de genere Russula in Europa. Tomo Secondo. AMB, Centro Studi Micologici, Trento, 801-1568.

Shimono Y, Kato M, Takamatsu S. 2004 - Molecular phylogeny of Russulaceae (Basidiomycetes; Russulales) inferred from the nucleotide sequences of nuclear large subunit rDNA. Mycoscience 45, 303-316.

Stöver BC, Müller KF. 2010 - TreeGraph 2: Combining and visualizing evidence from different phylogenetic analyses. BMC Bioinformatics 11, 7.

Swofford DL. 2004 - PAUP*: Phylogenetic analysis using parsimony and other methods. Version4.0b10. Sinauer, Sunderland.

Thiers B. 2018 - Continuously updated. Index Herbariorum: A global directory of public herbaria and associated staff. New York Botanical Garden's Virtual Herbarium. http://sweetgum.nybg.org/ih/. Accessed 11 January 2018

Trappe JM. 1962 - Fungus associates of ectotrophic mycorrhizae. Botanical Review 28(4), 538 606.

Wang W, Bau T. 2015 - Diversity of mycobiota and ecological distribution of macrofungi in Changbai Mountains. Journal of Jilin Agricultural University 31(1), 26-36.

White TJ, Bruns T, Lee S, Taylor J. 1990 - Amplification and direct sequencing of fungal ribosomal RNA genes for phylogenies. In: Innis MA, Gelfand DH, Sninsky JJ, White TJ (eds) PCR protocols, a guide to methods and applications. Academic, San Diego, 315-322.

Wu ZY. 1979 - The regionalization of Chinese flora. Acta Botanica Yunnanica 1(1), 1-22.

Xu HC. 1998 - Da Hinggan Ling Mountains Forests in China. Science Press, Beijing, 1-231.

Zhao RL, Li GJ, Sanchez-Ramirez S, Stata M et al. 2017 - A six-gene phylogenetic overview of Basidiomycota and allied phyla with estimated divergence times of higher taxa and a phyloproteomics perspective. Fungal Diversity 84(1), 43-74. 